\title{
Cardiovascular COMPLICATIONS IN THE ACQUIRED IMMUNODEFICIENCY SYNDROME
}

\author{
Giuseppe Barbaro ${ }^{1 *}$, Erika Ferrari Rafael da Silva ${ }^{2}$ \\ Trabalho realizado na Cardiology Unit, Department of Medical Pathophysiology, University "La Sapienza", Rome, Italy. HIV Treatment and Research Unit, Federal \\ University of São Paulo, São Paulo, SP
}

*Correspondência:

Viale Anicio Gallo, 63

00174 - Rome, Italy

Tel/Fax:+39-6-71028.89

g.barbaro@tin.it

\begin{abstract}
SUMMARY
The introduction of highly active antiretroviral therapy (HAART) has significantly improved the clinical outcome of HIV disease, with increased survival rates. However, the introduction of HAART has generated a contrast in the cardiac manifestations of AIDS. In developed countries, we observed an approximate $30 \%$ reduction in the prevalence of HIV-associated cardiomyopathy, possibly related to a reduction of opportunistic infections and myocarditis. In developing countries, however, where the availability of HAART is limited and the pathogenic impact of nutritional factors is significant, we observed an increase of approximately $32 \%$ in the prevalence of HIV-associated cardiomyopathy and a related high mortality rate from congestive heart failure. Also, some HAART regimens in developed countries, especially those including protease inhibitors, have been shown to cause, in a high proportion of HIV-infected patients, a iatrogenic metabolic syndrome (HIV-lipodystrophy syndrome). This is associated with an increased risk of atherosclerosis-related cardiovascular events even in young HIVinfected people. A better understanding of the molecular mechanisms responsible for this syndrome will lead to the discovery of new drugs that will reduce cardiovascular risk in HIV-infected patients receiving HAART.
\end{abstract}

KEY wORDS: HIV. Acquired Immunodeficiency Syndrome. Cardiovascular Diseases. HIV-Associated Lipodystrophy. Syndrome Highly Active Antiretroviral Therapy.

\section{INTRODUCTION}

Studies published before the introduction of highly active antiretroviral therapy (HAART) have tracked the incidence and course of human immunodeficiency virus (HIV) infection in relation to both pediatric and adult cardiac illnesses ${ }^{1}$. These studies showed that subclinical echocardiographic abnormalities independently predict adverse outcomes and identify high risk groups to be targeted for early intervention and therapy. Understanding the effects of HAART on the cardiovascular system is only possible after first understanding the effects of HIV co-infections ${ }^{2}$. HAART is only available to a minority of HIV infected individuals worldwide and studies published before the introduction of HAART continue to be applicable globally ${ }^{3}$, especially in developing countries ${ }^{4-6}$

\section{Hiv-associated cardiomyopathy}

Human immunodeficiency virus (HIV) disease is recognized as an important cause of dilated cardiomyopathy, with an estimated annual incidence of 15.9/1,000 before the introduction of HAART ${ }^{7}$. The importance of cardiac dysfunction is demonstrated by its effect on survival in the acquired immunodeficiency syndrome (AIDS). Median survival to AIDS-related death is 101 days in patients with left ventricular dysfunction and 472 days in patients with a normal heart on echocardiography at a similar infection stage ${ }^{7}$. The unadjusted hazard ratio for death in HIV-associated cardiomyopathy compared to idiopathic cardiomyopathy is 4.0; the ratio adjusted after multivariate analysis is $5.86^{7}$. The introduction of HAART regimens, by preventing opportunistic infections and reducing the incidence of myocarditis, has reduced the prevalence of HIV-associated cardiomyopathy by about $30 \%$ in developed countries ${ }^{8,9}$. However, the median prevalence of HIV-associated cardiomyopathy is increasing in developing countries (about 32\%), where the availability of HAART is scarce and the pathogenetic impact of nutritional factors is greater ${ }^{4-6}$.

\section{Myocarditis}

Myocarditis continues to be the best-studied cause of dilated cardiomyopathy in HIV disease. HIV-associated myocarditis may be defined as «a process characterized by a lymphocytic infiltrate of the myocardium with necrosis and/or degeneration of adjacent myocytes not typical of the ischemic damage associated 
with coronary artery disease in subjects infected by HIV with or without evidence of opportunistic infective agents» ${ }^{10}$. Myocarditis has been identified at autopsy in $40-52 \%$ of patients who died of AIDS before the introduction of HAART ${ }^{11}$. In the Gruppo Italiano per lo Studio Cardiologico dei pazienti affetti da AIDS (GISCA) autopsy series, histological diagnosis of myocarditis was made in 30 of 82 patients (37\%) with cardiac involvement ${ }^{11}$. Of 20 autopsy patients with dilated cardiomyopathy, 10 (83\%) had active myocarditis at histological examination of myocardial tissue specimens ${ }^{11}$.

Histological findings in HIV-infected patients with myocarditis do not substantially differ from those observed in HIV-uninfected patients. Lymphocytes, along with fewer macrophages, are distributed diffusely as single cells or in small clusters. Autopsy studies of AIDS patients who died of acute left ventricular dysfunction, almost invariably show a marked inflammatory infiltrate ${ }^{11,12}$. However, mild and focal mononuclear infiltrates are frequently observed in the hearts of AIDS patients, irrespective of the presence of cardiac symptoms ${ }^{11}, 12$. The intracardiac conduction system is sometimes affected in AIDS patients, generally as a complication of myocarditis. Primary involvement of the conduction system is possible as a consequence of opportunistic infections, drug cardiotoxicity, or primary location of HIV-1 in the specific conduction tissue ${ }^{11}$. Histological examination of myocardium specimens at autopsy may show mononuclear infiltration of the intracardiac conduction tissue, which is frequently associated with vasculitis and fragmentation of the bundles with lobulation and fibrosis. These findings are generally associated with electrocardiographic conduction abnormalities (e.g., left anterior hemiblock, left bundle branch block, and first-degree atrioventricular block $)^{11}$. In the GISCA autopsy series, 5/12 patients $(42 \%)$ with cardiomyopathy also had intracardiac conduction system alterations on histological examination. Two of them had lymphocytic infiltration of the conduction tissue as a complication of active myocarditis and the remaining three had fragmentation and fibromatous degeneration of the left bundle ${ }^{11}$.

\section{Nonviral myocarditis}

The most common opportunistic infectious agent associated with myocarditis in AIDS is Toxoplasma gondii, observed as often as $12 \%$ in one autopsy series of deaths from AIDS between 1987 and $1991^{12}$. There may be regional differences in the incidence of Toxoplasma gondii myocarditis, perhaps because the natural reservoir of organisms persists more easily in humid environments. Elevation of the myocardial fraction of creatine kinase may commonly occur with myocardial toxoplasmosis. Toxoplasma gondii organisms can produce a gross pattern of patchy irregular white infiltrates in the myocardium similar to non-Hodgkin's lymphoma. Microscopically, the myocardium shows scattered mixed inflammatory cell infiltrates with polymorphonuclear leukocytes, macrophages, and lymphocytes. Toxoplasma gondii can produce fairly variable inflammation along with myocardial fiber necrosis. The three microscopic patterns of involvement by Toxoplasma gondii include acute diffuse myocarditis, focal myocarditis, and presence of organisms without significant inflammation or necrosis ${ }^{10,12}$. In Toxoplasma myocarditis, true Toxoplasma gondii extracellular cysts, or pseudocysts within myocardial fibers, both of which contain the small $2-\mu$-sized bradyzoites, are often difficult to find, even if inflammation is extensive. Immunohistochemical staining may reveal free tachyzoites, organisms that are found outside of cysts. Otherwise, with routine hematoxylin and eosin staining, it is difficult to distinguish these free tachyzoites from fragments of inflammatory cells or myocytes that have undergone necrosis within the areas of inflammation ${ }^{10,12}$.

Fungal opportunistic infections of the heart occur infrequently in HIV-infected patients. They are often incidental findings at autopsy, and cardiac involvement is probably the result of widespread dissemination, as exemplified by Candida sp. and by the fungi Cryptoccocus neoformans, Coccidioides immitis, or Histoplasma capsulatum ${ }^{10-12}$. Fungal lesions are characterized grossly by the appearance of multiple small rounded white plaques. They may have a hemorrhagic border, particularly lesions caused by Aspergillus that can be angioinvasive. Microscopically, fungal lesions have variable inflammatory infiltrates and necrosis and a specific diagnosis is made by identifying yeast forms or hyphae of specific organisms, aided by standard histological stains such as Gomori methenamine silver or periodic acid Schiff ${ }^{10-12}$. The near absence of an inflammatory infiltrate accompanying fungal organisms is a manifestation of immune system failure with progression of AIDS to a late stage when opportunistic infections are more likely to be widely disseminated to organs such as the heart ${ }^{10-12}$. Patients living in endemic areas for Trypanosoma cruzi may rarely develop a pronounced myocarditis ${ }^{13,14}$. Mycobacterium avium-complex infection can be widely disseminated and involve the heart with microscopic lesions characterized by clusters of large macrophages filled with numerous acid-fast rod-shaped organisms ${ }^{10-12}$. Pneumocystis carinii can involve the heart in cases with widespread dissemination of this organism ${ }^{12}$. Grossly, the epicardium and cut surfaces of the myocardium may have a sandpaper-like quality due to the presence of multiple pinpoint foci of calcification. Microscopically, this calcification is not accompanied by significant inflammatory cell infiltrates, but there may be deposits of amorphous granular pink exudate similar to that seen in alveoli with Pneumocystis carinii pneumonia ${ }^{10,12}$. The cysts may be difficult to recognize, even with Gomori methenamine silver stain, and diagnosis is aided by immunohistochemical staining ${ }^{10,12}$.

\section{Viral myocarditis}

Histology and immunohistochemistry rarely detect the presence of viruses in the myocardium. However, in situ hybridization or polymerase chain reaction studies reveal a high frequency of either cytomegalovirus or HIV-1 or both, in AIDS patients with lymphocytic myocarditis and severe left ventricular dysfunction ${ }^{11,15}$. These data support the hypothesis that, at least in a subset of patients, HIV-1 has a pathogenetic action and possibly influences the clinical evolution toward dilated cardiomyopathy. HIV-1 nucleic acid sequences were detected at autopsy by in situ DNA hybridization in 35\% of the GISCA patients with cardiac involvement; $86 \%$ of them had active myocarditis at histological examination ${ }^{11}$. Among patients with myocarditis, coinfection with coxsackievirus B3 was documented in $32 \%$, with Epstein-Barr virus in $8 \%$, and with cytomegalovirus in $4 \%^{11}$. In autopsy biopsy samples, myocytes with a positive hybridization signal were sparse, usually only one to four cells 
per section ${ }^{11}$. Although about $70 \%$ of patients with positive hybridization signals had active myocarditis at histological examination, most myocytes with a positive hybridization signal were not surrounded by inflammatory cells ${ }^{11}$. In the GISCA autopsy series, HIV-1 was documented by in situ hybridization in $83 \%$ of patients with myocarditis ${ }^{11}$.

Coinfection with other viruses seems to have an important etiopathogenetic role. The GISCA autopsy records show that $83 \%$ of patients with myocarditis and $50 \%$ of those with dilated cardiomyopathy were coinfected with cardiotropic viruses (usually, coxsackievirus B3 and cytomegalovirus ${ }^{11}$ ). Herskowitz et al. used in situ hybridization to detect myocardial cytomegalovirus infection in $48 \%$ of HIV-infected patients with myocarditis and left ventricular dysfunction who underwent endomyocardial biopsy ${ }^{15}$. Bowles et al. used polymerase chain reaction and found that $42 \%$ of HIV-infected patients with cardiomyopathy had cytomegalovirus or adenovirus in the myocardial tissue ${ }^{16}$. Some patients with adenovirus coinfection had congestive heart failure but not myocarditis, suggesting that the virus may be virulent without an associated inflammatory response.

\section{Myocardial cytokine expression}

Myocardial dendritic cells may play a role in the interaction between HIV-1 and the cardiac myocyte and in the activation of cytotoxic cytokines ${ }^{17}$. Dendritic cells can initiate the primary immunologic response and present the antigen to T-lymphocytes. The interaction between dendritic cells and T-lymphocytes, particularly CD8 cells, could promote a local elevation in the multifunctional cytokine tumor necrosis factor-(TNF) alpha, which can also be produced and secreted by infected macrophages $^{18}$. TNF-alpha produces a negative inotropic effect by altering intracellular calcium homeostasis, possibly by inducing nitric oxide (NO) synthesis, which also reduces myocyte contractility. Kan et al. demonstrated that HIV gp120 enhances NO production by cardiac myocytes through p38 MAP kinase-mediated NK-kB activation ${ }^{19}$. Myocarditis and dilated cardiomyopathy are associated with markedly elevated cytokine production, but the elevations may be highly localized within the myocardium, making peripheral cytokine levels uninformative ${ }^{20}$. When myocardial biopsies from patients with HIV-associated cardiomyopathy are compared to samples from patients with idiopathic dilated cardiomyopathy, the former stain more intensely for both TNFalpha and inducible nitric oxide synthase (iNOS). Staining is particularly intense in samples from patients with a myocardial viral infection and correlates with CD4 count, independent of antiretroviral treatment ${ }^{20}$. Staining is also more intense in samples from patients with HIV-associated cardiomyopathy coinfected with coxsackievirus B3, cytomegalovirus, EpsteinBarr virus or adenovirus ${ }^{20}$. Moreover, staining for iNOS is more intense in samples from patients coinfected with HIV-1 and coxsackievirus B3 or cytomegalovirus than in samples from patients with idiopathic dilated cardiomyopathy and myocardial infection with coxackievirus B3 or who had adenovirus infection alone $^{20}$. In patients with HIV-associated dilated cardiomyopathy and more intense iNOS staining, the survival rate was significantly lower: those whose samples stained more than 1 optical density unit had a hazard ratio of mortality of $2.57^{20}$. Survival in HIV-infected patients with less intense staining was not significantly different from survival in patients with idiopathic dilated cardiomyopathy ${ }^{20}$.

\section{Autoimmunity as a contributor to HIV-associated cardiomyo- pathy}

Cardiac-specific autoantibodies (anti-alpha-myosin autoantibodies) are more common in HIV-infected patients with dilated cardiomyopathy than in HIV-infected patients with healthy hearts. Currie et al. reported that HIV-infected patients were more likely to have specific cardiac autoantibodies than were HIVuninfected controls ${ }^{21}$. Those with echocardiographic evidence of left ventricular dysfunction were particularly likely to have cardiac autoantibodies, supporting the theory that cardiac autoimmunity plays a role in the pathogenesis of HIV-associated cardiomyopathy and suggesting that cardiac autoantibodies could be used as markers of left ventricular dysfunction in HIV-infected patients with previously normal echocardiographic findings ${ }^{21}$. In addition, monthly intravenous immunoglobulin in HIV-infected pediatric patients minimizes left ventricular dysfunction, increases left ventricular wall thickness, and reduces peak left ventricular wall stress. This suggests that both impaired myocardial growth and left ventricular dysfunction may be immunologically mediated ${ }^{22}$. These effects may be the result of immunoglobulins inhibiting cardiac autoantibodies by competing for Fc receptors, or of immunoglobulins dampening the secretion or effects of cytokines and cellular growth factors ${ }^{22}$. These findings suggest that immunomodulatory therapy might be helpful in HIV-infected patients with declining left ventricular function, although further study of this possible therapy is needed.

\section{Nutritional deficiencies as a factor in left ventricular dysfunc- tion}

Nutritional deficiencies are common in HIV infection and may contribute to ventricular dysfunction independently of HAART. Malabsorption and diarrhea can both lead to trace element deficiencies which have been directly or indirectly associated with cardiomyopathy ${ }^{23,24}$.Selenium, as a component of glutathione peroxidase, is involved in the antioxidant response in cells and tissues. Selenium deficiency is associated with congestive cardiomyopathy and skeletal-muscle disorders. Furthermore, low levels of selenium or other macronutrients may be responsible for the cardiotoxic effects of coxsackievirus B3 and for the ability of these viruses to enhance the toxic effects of zidovudine on skeletal muscle. Both findings may be relevant to selenium-related ventricular dysfunction in HIV-infected patients ${ }^{24,25}$, especially in developing countries ${ }^{6}$. Selenium replacement may reverse cardiomyopathy and restore left ventricular function in seleniumdeficient patients ${ }^{26}$. HIV infection may also be associated with altered levels of vitamin $\mathrm{B}_{12}$, carnitine, growth hormone, and thyroid hormone, all of which have been associated with left ventricular dysfunction 23,24 .

\section{Autonomic dysfunction as a factor in left ventricular dysfunc- tion}

There is evidence of an altered autonomic function in HIVinfected patients ${ }^{27,28}$.In a previous study, autonomic dysfunction in HIV-infected patients was assessed by a significant decrease of the corrected coefficients of electrocardiographic R-R interval 
variation $(\mathrm{CV} \mathrm{c})$ compared to healthy controls ${ }^{29}$. CVc correlated significantly with CD4 count and with values of hepatic, plasmatic, lymphocyte and erythrocyte concentrations of reduced glutathione as well as with erythrocyte malonyldialdehyde levels as the expression of increased lipoperoxidation ${ }^{29}$. This correlation was more evident in patients coinfected with hepatitis $C$ virus (HCV) where the lipoperoxidation process and production of free radicals of oxygen are enhanced by the inflammatory process induced by HIV/HCV coinfection ${ }^{29}$. According to this study, the autonomic dysfunction in HIV-infected patients may be the expression of a reduced response to the oxidative stress related to HIV infection because of a systemic depletion of reduced glutathione associated with the state of immunodeficiency ${ }^{29}$.

Left ventricular asynergy may develop due to regional differences in the distribution of cardiac sympathetic nerve endings, even in the context of acute myocarditis. In fact, an alteration of catecholamine dynamics (or autonomic function) has been associated with a transient extensive akinesis of the apical and mid portions of the left ventricle with hypercontraction of the basal segment (takotsubo-like dysfunction) in an HIV-infected patient with cytomegalovirus myocarditis ${ }^{30}$.

\section{Left ventricular dysfunction caused by drug cardiotoxicity}

Studies of transgenic mice suggest that zidovudine is associated with diffuse destruction of the cardiac mitochondrial ultrastructure and inhibition of mitochondrial DNA replication ${ }^{31}$. This mitochondrial dysfunction may result in lactic acidosis, which could also contribute to myocardial cell dysfunction. However, in a study of infants born to HIV-infected mothers followed from birth to age 5, perinatal exposure to zidovudine was not found to be associated with acute or chronic abnormalities in left ventricular structure or function ${ }^{32}$. Other nucleoside reverse transcriptase inhibitors, such as didanosine, zalcitabine or lamivudine, do not seem to promote or prevent dilated cardiomyopathy. In AIDS patients with Kaposi's sarcoma, reversible cardiac dysfunction was associated with prolonged, high-dose therapy with interferon alpha ${ }^{33}$. High-dose interferon alpha treatment is not associated with myocardial dysfunction in other patient populations, so it has been proposed that it may have a synergistic effect with HIV-1 infection ${ }^{33}$. Doxorubicin (adriamycin), which is used to treat AIDS-associated Kaposi's sarcoma and non-Hodgkin's lymphoma, has a dose-related effect on dilated cardiomyopathy ${ }^{34}$, as does foscarnet sodium when used to treat cytomegalovirus esophagitis ${ }^{35}$.

\section{Hiv infection opportunistic infections and vascular disease Endothelial dysfunction}

Endothelial dysfunction and injury have been described in HIV infection ${ }^{36}$. Endothelial activation in HIV-1 infection may also be caused by cytokines (e.g., TNF-alpha) secreted in response to mononuclear or adventitial cell activation by the virus, or may be a direct effect of the secreted HIV-1-associated proteins gp 120 and tat (transactivator of viral replication) on the endothelium with possible induction of apoptosis process ${ }^{37}$. Opportunistic agents, such as cytomegalovirus, as well as human herpes virus-8 (a virus involved in the development of AIDS-associated Kaposi's sarcoma), frequently co-infect HIV-infected patients and may contribute to development of endothelial damage. In spite of all these observations, the clinical consequences of HIV-1 and opportunistic agents on endothelial function have not been elucidated yet.

\section{Vasculitis}

A wide range of inflammatory vascular diseases including polyarteritis nodosa, Henoch-Schonlein purpura and druginduced hypersensitivity vasculitis may develop in HIV-infected individuals. Kawasaki-like syndrome ${ }^{38-40}$ and Takayasu's arteritis $^{41}$ have also been described. The course of vascular disease may be accelerated in HIV-infected patients because of atherogenesis stimulated by HIV-infected monocyte-macrophages, possibly via altered leukocyte adhesion or arteritis ${ }^{39}$.

The incidence of vasculitis (excluding adverse drug reactions) in HIV infection is estimated to be about $1 \%{ }^{39}$. Some HIV-infected patients have a clinical presentation resembling systemic lupus erythematosus including vasculitis, arthralgias, myalgias, and autoimmune phenomena with a low titer positive antinuclear antibody, coagulopathy with lupus anticoagulant, hemolytic anemia, and thrombocytopenic purpura ${ }^{39}$. Hypergammaglobulinemia from polyclonal B-cell activation may be present, but often diminishes in the late stages of AIDS. Specific autoantibodies to double-stranded DNA, Sm antigen, RNP antigen, SSA, SSB and other histones may be found in the majority of HIV-infected persons, but their significance is unclear ${ }^{39}$.

\section{HIV infection and coronary arteries}

The association between viral infection (cytomegalovirus or HIV-1 itself) and coronary artery lesions is not clear. HIV-1 sequences have been detected by in situ hybridization in the coronary vessels of an HIV-infected patient who died from acute myocardial infarction ${ }^{42}$. Potential mechanisms through which HIV-1 may damage coronary arteries include activation of cytokines and cell-adhesion molecules and alteration of major histocompatibility complex class I molecules on the surface of smooth-muscle cells ${ }^{42}$. It is also possible that HIV-1-associated protein gp 120 may induce smooth-muscle cell apoptosis through a mitochondrion-controlled pathway by activation of inflammatory cytokines ${ }^{37}$.

\section{Pericardial Effusion}

The prevalence of pericardial effusion in asymptomatic HIV-infected patients has been estimated at $11 \%$ before the introduction of HAART ${ }^{43}$. According to some retrospective data, prevalence of pericardial effusion in HIV-infected patients is reduced by about 30\%-35\% after the introduction of HAART, with a trend similar to that observed for HIV-associated cardiomyopathy ${ }^{8}$. On the contrary, in developing countries, prevalence of pericardial effusion is increased by $35 \%-40 \%$, mostly related to Mycobacteria infections ${ }^{4,5}$. HIV infection should be included in the differential diagnosis of unexplained pericardial effusion or tamponade. Pericardial effusion in HIV disease may be related to opportunistic infections (e.g., Mycobacterium tuberculosis, Mycobacterium avium-complex infection) or to malignancy (e.g., non-Hodgkin lymphoma), but most often a clear etiology is not found. The effusion may be part of a generalized serous 
effusive process, also involving pleural and peritoneal surfaces. This "capillary leak" syndrome is possibly related to enhanced cytokine expression (e.g., TNF-alpha) in the later stages of HIV disease and correlates with the immunodeficiency state of the patient 8,44 .

\section{Endocarditis}

Prevalence of infective endocarditis did not vary in HIVinfected patients who use intravenous drugs after the introduction of HAART even in developed countries, being similar to that observed in HIV-uninfected intravenous drug addicts ${ }^{7}$. Estimates of infective endocarditis prevalence vary from $6.3 \%$ to $34 \%$ of HIV-infected patients who use intravenous drugs independently of HAART ${ }^{11}$. Among intravenous drug addicts, the tricuspid valve is most frequently affected and the most frequent agents are Staphylococcus aureus ( $>75 \%$ of cases), Streptococcus pneumoniae, Haemophilus influenzae, Candida albicans, Aspergillus fumigatus and Cryptococcus neoformans ${ }^{11}$. Avirulent bacteria, such as the HACEK group (Haemophilus species, actinomycetemcomitans, Cardiobacterium hominis, Eikenella corrodens and Kingella kingae), which are often part of the, endogenous flora, of the mouth, can cause endocarditis in HIV-infected patients ${ }^{12}$. Vegetations may form on the tricuspid or pulmonary valves with resultant pulmonary embolism and consequent septic pulmonary infarction which appear as multiple opacities on chest radiograms. Systemic emboli often involve coronary arteries, spleen, bowel, extremities and central nervous system. Cardiac rhythm alterations (i.e., atrioventricular block) may suggest the presence of an abscess near to the atrioventricular node. Peripheral pulses should be examined for signs of embolic occlusion or pulsating mass suggesting mycotic aneurysm. Mycotic aneurysms may occur in the intracranial arteries potentially leading to intracranial hemorrhage ${ }^{45}$. Patients with HIV infection generally have similar presentations and survival ( $85 \%$ vs. 93\%) from infective endocarditis as those without HIV. However, patients with late-stage HIV disease have about 30\% higher mortality with endocarditis than asymptomatic HIV-infected patients, which may be related to the degree of immunodeficiency ${ }^{46}$. Nonbacterial thrombotic endocarditis, also known as marantic endocarditis, had a prevalence of $3 \%-5 \%$ in AIDS patients, mostly in patients with HIVwasting syndrome, before the introduction of HAART ${ }^{11}$. Friable endocardial vegetations, affecting predominantly the left-sided valves, consisting of platelets within a fibrin mesh with few inflammatory cells characterize it ${ }^{11}{ }^{12}$. Marantic endocarditis is now more frequently observed in developing countries, with a high incidence (about 10\%-15\%) and mortality by systemic embolization ${ }^{4,5}$.

\section{HIV-associated Pulmonary Hypertension}

The incidence of HIV-associated pulmonary hypertension has been estimated in $1 / 200$, much higher than $1 / 200,000$ found in the general population and is increased after introduction of HAART ${ }^{47}$. The histopathology of HIV-associated pulmonary hypertension is similar to that of primary pulmonary hypertension. The most common alteration in HIV-associated pulmonary hypertension is the plexogenic pulmonary arteriopathy, while thrombotic pulmonary arteriopathy and pulmonary veno-occlusive disease are rarer histological findings ${ }^{12}$. This observation may suggest that similar etiopathogenetic mechanisms are at the basis of both HIV-associated pulmonary hypertension and primary pulmonary hypertension. A key pathogenetic role is played by pulmonary dendritic cells which are not sensitive to HAART and may hold HIV-1 on their surfaces for extended time periods ${ }^{47}$. Infection of these cells by HIV-1 causes a chronic release of cytotoxic cytokines (e.g., endothelin-1, interleukin-6, interleukin-1 beta and TNF-alpha) contributing to vascular plexogenic lesions and progressive tissue damage, independently of opportunistic infections, stage of HIV disease and HAART regimens ${ }^{47}$. Activation of alpha- 1 receptors and genetic factors (increased frequency of HLA-DR6 and DR52) have also been hypothesized in the pathogenesis of HIV-associated pulmonary hypertension ${ }^{47}$.

\section{Cardiac Involvement in Aids-Associated NeOPLASMS}

The prevalence of cardiac Kaposi's sarcoma in AIDS patients ranges from $12 \%$ to $28 \%$ in retrospective autopsy studies performed in the pre-HAART era ${ }^{11}$. Cardiac involvement with Kaposi's sarcoma usually occurs when widespread visceral organ involvement is present. Lesions typically measure less than $1 \mathrm{~cm}$ and may be pericardial or, less frequently, myocardial, and are only rarely associated with obstruction, dysfunction, morbidity, or mortality. Microscopically, there are atypical spindle cells lining slit-like vascular spaces ${ }^{12}$. Non-Hodgkin lymphoma involving the heart is not frequent in AIDS ${ }^{11}{ }^{12}$. Most are high-grade B-cell (small non-cleaved) Burkitt-like lymphomas, with the rest classified as diffuse large B cell lymphomas (in the REAL classification). Lymphomatous lesions may appear grossly as either discreet localized or more diffuse nodular to polypoid masses $11,48,49$. Most involve the pericardium, with variable myocardial infiltration ${ }^{11,48,49}$. There is little or no accompanying inflammation and necrosis. Prognosis of patients with HIV-associated cardiac lymphoma is generally poor because of widespread organ involvement, although some patients treated with combination chemotherapy have experienced clinical remission ${ }^{50}$. The introduction of HAART led to a reduction by about $50 \%$ in the overall incidence of cardiac involvement by Kaposi's sarcoma and nonHodgkin lymphomas. This may be attributable to the improved immunologic state of patients and prevention of opportunistic infections (human herpes virus- 8 and Epstein-Barr virus) known to play an etiologic role in these neoplasms. On the contrary, an increased prevalence of cardiac involvement of AIDS-associated tumors may be observed in developing countries in relation to the scanty availability of HAART ${ }^{4,7}$.

\section{Haart-associated lipodystrophy and metabolic syndrome}

The introduction of HAART has significantly modified the course of HIV disease, with longer survival and improved quality of life in HIV-infected subjects. However, HAART regimens, especially those including protease inhibitors (PI) have shown to cause, in a high proportion of HIV-infected patients, somatic (lipodystrophy/lipoatrophy) and metabolic (dyslipidemia,insulinresistance) changes that in the general population are associated with an increased risk of cardiovascular disease, producing an intriguing clinical scenario. 
HIV-associated lipodystrophy or lipoatrophy, unreported prior to introduction of HAART, was first described in $1998^{51}$. It is characterized by the presence of a dorsocervical fat pad (also known as buffalo hump), increased abdominal girth and breast size, lipoatrophy of subcutaneous fat of the face, buttocks and limbs, and prominence of veins on the limbs. The overall prevalence of at least one physical abnormality is thought to be about $50 \%$ in otherwise healthy HIV-infected patients receiving HAART, although reported rates range from $18 \%$ to $83 \% 52,53$. Differences in rates might be influenced by age, gender, the type and duration of antiretroviral therapy, and the lack of an objective and validated case definition ${ }^{52,53}$. As in genetic lipodystrophy syndromes, fat redistribution may precede the development of metabolic complications in HIV-infected patients receiving HAART. Among HIV-infected patients with lipodystrophy, increased total serum and low density lipoprotein cholesterol and triglyceride levels have been observed in about 70\%, whereas insulin resistance (elevated C-peptide and insulin) and type 2 diabetes mellitus have been observed in $8 \%$ to $10 \% 52,53$. The severity of these metabolic abnormalities increases with growing severity of lipodystrophy, and are associated with a raised risk of cardiovascular events: approximately 1.4 cardiac events per 1000 years of therapy according to the Framingham score ${ }^{53}$.

The pathogenesis of HAART-associated lipodystrophy and metabolic syndrome is complex and a number of factors are involved, including direct effects of HAART on lipid metabolism, endothelial and adipocyte cell function, and mitochondrial dysfunction.

\section{Molecular mechanisms}

\section{PI-Associated lipodystrophy and metabolic alterations}

$\mathrm{PI}$ targets the catalytic region of HIV-1 protease. This region is homologous with regions of two human proteins that regulate lipid metabolism: cytoplasmic retinoic-acid binding protein-1 (CRABP-1) and low density lipoprotein-receptor-related protein $(\mathrm{LRP})^{54}$. It has been hypothesized, although without strong experimental support, that this homology may allow PI to interfere with these proteins, which may be the cause of metabolic and somatic alterations that develop in $\mathrm{Pl}$-treated patients ${ }^{54}$. The hypothesis is that PI inhibit CRABP-1-modified and cytochrome P450-3A-mediated synthesis of cis-9-retinoic acid and peroxisome proliferator-activated receptor type-gamma heterodimer. The inhibition increases the rate of apoptosis of adipocytes and reduces the rate at which pre-adipocytes differentiate into adipocytes, with the final effect of reducing triglyceride storage and increasing lipid release. PI-binding to LRP would impair hepatic chylomicron uptake and endothelial triglyceride clearance, resulting in hyperlipidemia and insulin resistance ${ }^{54}$.

Some data indicate that $\mathrm{Pl}$-associated dyslipidemia may be caused, at least in part, either by PI-mediated inhibition of proteasome activity and accumulation of the active portion of sterol regulatory element-binding protein (SREBP)-1c in liver cells and adipocytes ${ }^{55}$, or by apo-CIII polymorphisms in HIV-infected patients ${ }^{56,57}$. Sequence homologies have been described between HIV-1 protease and human site-1 protease (S1P), which activates SREBP-1C and SREBP-2 pathways. A polymorphism in the S1P/SREBP-1C gene confers a difference in risk for development of an increase in total cholesterol with
PI-therapy. This suggests presence of a genetic predisposition to hyperlipoproteinemia in Pl-treated patients ${ }^{58}$. There is also evidence that PI directly inhibit the uptake of glucose in insulinsensitive tissues, such as fat and skeletal muscle, by selectively inhibiting the glucose transporter Glut ${ }^{59}$.

\section{TNF-alpha and lipodystrophy}

The relationship between the degree of insulin resistance and levels of soluble type-2-TNF-alpha receptor suggests that an inflammatory stimulus may contribute to development of HIV-associated lipodystrophy ${ }^{60}$. TNF-alpha activates 11 -betahydroxysteroid dehydrogenase type-1, which converts inactive cortisone into active cortisol. The activity of this enzyme is higher in visceral fat, compared to subcutaneous fat. Visceral fat is able to locally produce cortisol which could act inside adipocytes and increase lipid accumulation ${ }^{61}$.

\section{Mitochondrial dysfunction and lipodystrophy}

There is evidence of nucleoside-induced mitochondrial dysfunction in HIV-infected patients treated with nucleosidecontaining HAART, because lipodystrophy with peripheral fat wasting is associated with a decrease in subcutaneous adipose tissue mitochondrial DNA content ${ }^{62}$. Disrupted pools of nucleotide precursors and inhibition of DNA pol-gamma by specific nucleoside reverse transcriptase inhibitors are mechanistically important in mitochondrial toxicity ${ }^{63}$. This effect has been especially described with use of stavudine and was correlated with length of exposure to this drug64. HAART regimens with didanosine plus stavudine are more likely to produce a greater increase in serum lactate and lipodystrophy than therapies based on zidovudine plus lamivudine within the first year of therapy ${ }^{62}$. Substitution of stavudine by abacavir or zidovudine improves mitochondrial indices and fat apoptosis in the setting of lipoatrophy ${ }^{65}$.

\section{Adipocytokines and lipodystrophy}

Adipocytes secrete a range of adipocytokines which control insulin sensitivity ${ }^{66}$. There is evidence that an adipocytokine, adiponectin, a protein product of the apM1 gene, which is expressed exclusively in adipocytes, plays a role in development of HIV-associated lipodystrophy as well as in congenital and acquired lipodystrophies in non-HIV infected subjects ${ }^{67}$. In vitro and animal studies and cross-sectional studies in humans have shown that adiponectin is inversely correlated with features of HAART-associated metabolic syndrome. This syndrome has recently been linked to a quantitative trait locus on chromosome $3 q 27$, the location of the apM1 gene $66,68,69$. These studies have shown that both adiponectin levels and the adiponectin-to-leptin ratio are positively correlated with features of HAART-associated metabolic syndrome ${ }^{66,68,69}$. According to these studies, this ratio could be used to predict insulin sensitivity and potential cardiovascular risk in HIV-infected patients receiving HAART.

\section{HAART and cardiovascular disease HAART-associated endothelial dysfunction}

In vitro data reported by Fiala et al. suggest that some HAART regimens, such as those including zidovudine, some non-nucleoside reverse transcriptase inhibitors (e.g. efavirenz) 
and $\mathrm{PI}$ disrupt endothelial cell junctions and cytoskeleton action of the endothelial cells leading to endothelial dysfunction ${ }^{70}$. These findings are in agreement with those previously reported in vivo by Stein et al. ${ }^{71}$ and in vitro by Zhong et al. ${ }^{72}$. In particular, Zhong et al. demonstrated that ritonavir at concentrations near clinical plasma levels is able to directly cause endothelial mitochondrial DNA damage and cell death mainly through a necrosis pathway but not through apoptosis ${ }^{72}$. Chai et al. investigated and compared the effects of $\mathrm{PI}$ on isolated porcine arteries and observed a reduced endothelial NO synthase expression and increased levels of superoxide anion as expression of increased endothelial oxidative stress ${ }^{73}$. The HIV-1 entry inhibitor TAK-799 is an antagonist for the chemokine receptors CCR5 and CXCR3, which are expressed on leucocytes, especially T-helper-1 cells, and these receptors, may be involved in recruitment of these cells to atherosclerotic vascular lesions ${ }^{74}$. In low-density lipoprotein receptordeficient mice treated with TAK-799, the number of T cells in the atherosclerotic plaque was reduced by $95 \%$, concurrently with a $98 \%$ reduction in the relative interferon-gamma area ${ }^{74}$. According to this study, TAK-779 not only suppresses HIV-1 entry via blockade of CCR5 but also attenuates atherosclerotic lesion formation by blocking influx of T-helper-1 in the atherosclerotic plaque $^{74}$. Since TAK-799 impairs atherogenesis, treatment with TAK-799 could be beneficial for young HIV-infected patients facing lifelong HAART regimens.

\section{HAART-associated vasculitis}

Drug-induced hypersensitivity vasculitis is common in HIVinfected patients receiving HAART ${ }^{39}$.Vasculitis associated with drug reactions typically involves small vessels and has a lymphocytic or leukocytoclastic histopathology. The pathologic mechanisms include T-cell recognition of haptenated proteins or deposition of immune complexes in blood-vessel walls ${ }^{39}$. Medical practitioners need to be especially aware of abacavir hypersensitivity reactions because of the potential for fatal outcomes. Hypersensitivity reactions of this type should always be considered as a possible etiology for a vasculitic syndrome in an HIV-infected patient ${ }^{39}$.

\section{HAART-associated coagulation disorders}

HIV-infected patients receiving HAART, especially those with fat redistribution and insulin resistance, might develop coagulation abnormalities, including increased levels of fibrinogen, D-dimer, plasminogen activator inhibitor-1, and tissue-type plasminogen activator antigen, or deficiency of protein $\mathrm{S}^{75,76}$. For instance, protein S deficiency has been reported in up to $73 \%$ of HIV-infected men ${ }^{75,76}$. These abnormalities have been associated with thromboses involving veins and arteries and seem to be related to HAART regimens that include $\mathrm{Pl}^{77}$. Thrombocytosis has been reported in $9 \%$ of patients receiving HAART, with cardiovascular complications in up to $25 \%$ of cases $^{78}$.

\section{HAART-associated systemic arterial hypertension}

Prevalence of arterial hypertension in HIV disease has been estimated to be about $20-25 \%$ prior to introduction of HAART ${ }^{79}$. HIV-associated endothelial dysfunction and injury, autoimmune reaction to viral infection (vasculitis), and renal disease have been hypothesized to play a role in the pathogenesis of HIV-associated hypertension. Endothelial dysfunction has been described in association with visceral fat accumulation and related metabolic alterations (e.g., insulin resistance) and activation of proinflammatory cytokines (TNF-alpha, IL-6), as well as with a direct action of drugs included in HAART regimens. HIV-associated renal impairment can present as acute or chronic kidney disease; it can be caused directly or indirectly by HIV-1 and/or by drug-related effects that are directly nephrotoxic or lead to changes in renal function by inducing metabolic vasculopathy and renal damage ${ }^{80}$. Chronic renal disease can be caused by multiple pathophysiologic mechanisms, leading to HIV-associated nephropathy, a form of collapsing focal glomerulosclerosis, thrombotic microangiopathy, and various forms of immune complex glomerulonephritis ${ }^{80}$. Arterial hypertension, even in agreement with the Adult Treatment Panel-III guidelines $^{81}$, is currently considered part of HAART-associated metabolic syndrome ${ }^{82}$. It appears to be related to $\mathrm{Pl}$-induced lipodystrophy ${ }^{83}$ and metabolic disorders, especially to elevated fasting triglycerides and insulin resistance ${ }^{82,84}$.

\section{HAART-associated coronary artery disease}

HIV-infected patients receiving HAART with preexisting additional risk factors (e.g. hypertension, diabetes or increased plasma homocysteine levels) might be at raised risk of developing coronary artery disease because of accelerated atherosclerosis. Conflicting data exist, however, on the relationship between HAART and incidence of acute coronary syndromes, such as unstable angina or myocardial infarction, among HIV-infected patients receiving $\mathrm{Pl}$-containing HAART ${ }^{85-89}$. Differences in the study design, selection of patients and statistical analyses might explain this disparity. However, longer exposure to HAART and/ or PI seem to increase the risk of myocardial infarction. Results of the Data Collection on Adverse Events of Anti-HIV Drugs study showed that HAART therapy is associated with a $26 \%$ relative risk increase in the rate of myocardial infarction per year of HAART exposure ${ }^{90}$.

\section{HAART-associated peripheral vascular disease}

The issue of surrogate markers of subclinical atherosclerosis has also been addressed. A study was performed on a cohort of 168 HIV-infected patients to measure the intima-media thickness (IMT) and assess indirectly the cardiovascular risk. In this population a high prevalence of atherosclerotic plaques within the femoral or carotid arteries was observed, but their presence was not associated with use of $\mathrm{PI}^{91}$. Similar results were also reported by Hsue et al. ${ }^{92}$ and by Currier et al. ${ }^{93}$ in case-control studies suggesting that traditional risk factors may contribute to atherosclerosis in HIV-infected patients independently of PI exposure. Alonso-Villaverde et al. reported that HIV-infected patients with subclinical atherosclerosis have higher circulating levels of monocyte chemoattractant protein-1 (MCP-1), especially of the allele MCP-1-2518G, compared to patients without atherosclerotic lesions, independently of HAART regimen ${ }^{94}$.Different results were reported by Maggi et al. who observed a higher than expected prevalence of premature carotid lesions in PI-treated patients compared to $\mathrm{PI}$-naive patients ${ }^{95}$. Similar results have been reported in a study by Jerico et al. in 68 HIV-infected patients $^{96}$. These authors conclude, stating that HAART should be 
considered a strong, independent predictor for the development of subclinical atherosclerosis in HIV-infected patients, regardless of known major cardiovascular risk factors and atherogenic metabolic abnormalities induced by this therapy ${ }^{96}$. The impact of individual measures to reduce cardiovascular risk and progression of atherosclerosis has been addressed by Thiebaut et al. ${ }^{97}$. According to these authors, the increased use of lipid-lowering agents, of PI-free HAART regimes and reduction of smoking may decrease the IMT in HIV-infected patients over time ${ }^{97}$. In spite of these different results, markers of subclinical atherosclerosis should be carefully assessed in HIV-infected patients receiving HAART, especially in those with lipodystrophy.

\section{New markers defining cardiovascular risk in patients receiving HAART}

New insights in defining the cardiometabolic risk in patients with HAART-associated metabolic syndrome have been provided recently by the echocardiographic measurement of the epicardial adipose tissue. Epicardial adipose tissue is the true visceral fat of the heart and is significantly correlated with abdominal visceral fat measured by MRI ${ }^{98}$. Given its potential as an easy and reliable marker of visceral fat, epicardial fat has been recently evaluated in patients with HIV-lipodystrophy syndrome ${ }^{98}$. In these patients, echocardiographic epicardial fat correlated with intra-abdominal visceral fat, carotid IMT, and clinical parameters of the metabolic syndrome (especially waist circumference, blood pressure, fasting glucose, and insulin and markers of fatty liver ${ }^{98-100}$. Taken together, these findings suggest that echocardiographic assessment of epicardial fat may have the potential to be a simple and reliable marker of visceral adiposity and increased cardiovascular risk in patients with HIV-lipodystrophy syndrome ${ }^{98,99}$.

\section{Conclusion}

Cardiac and pulmonary complications of HIV disease are generally late manifestations and may be related to prolonged effects of immunosuppression and a complex interplay of mediator effects from opportunistic infections, viral infections, autoimmune response to viral infection, drug-related cardiotoxicity, nutritional deficiencies, and prolonged immunosuppression. In developed countries HAART has significantly reduced prevalence of HIV-associated cardiomyopathy which heavily influenced the prognosis of HIV-infected patients in the preHAART period. However, HAART-associated metabolic syndrome is an increasingly recognized clinical entity. The atherogenic effects of PI-including HAART may synergistically promote acceleration of coronary and cerebrovascular disease and increase the risk of death from myocardial infarction and stroke even in young HIV-infected people. A better understanding of the molecular mechanisms responsible for this syndrome will lead to discovery of new drugs that will reduce the cardiovascular risk in HIV-infected patients receiving HAART.

* This article is a revised and updated version of the chapter: Barbaro G. "Pathogenesis of cardiovascular complications in the acquired immunodeficiency syndrome". In: Watson RR, Larson DF, editors. Immune dysfunction and immunotherapy in heart disease. Blackwell Futura; 2007:135-51.

\section{Resumo}

\section{Complicações cardiovasculares na síndrome de Imunodefici- ÊNCIA ADQUIRIDA}

A introdução da terapia antitroviral altamente potente (HAART) melhorou significativamente a evolução clínica da infecção pelo HIV com um aumento nas taxas de sobrevida. Apesar deste benefício, o uso da HAART gerou contrastes nas manifestações cardíacas da Aids. Nos países desenvolvidos, observou-se uma redução de aproximadamente $30 \%$ na prevalência de cardiomiopatia associada ao HIV, possivelmente relacionada à redução das infecções oportunistas e da miocardite. Nos países em desenvolvimento, entretanto, aonde a disponibilidade da HAART é limitada e o impacto patogênico dos fatores nutricionais é significante, observou-se um aumento de 32\% na prevalência de cardiomiopatia e uma alta taxa de mortalidade relacionada com a insuficiência cardíaca congestiva. Além disso, alguns tipos de HAART nos países desenvolvidos, especialmente aqueles que incluem inibidores da protease, têm causado em uma alta proporção de pacientes, uma síndrome metabólica iatrogênica (síndrome da lipodistrofia relacionada ao HIV) que está associada ao aumento do risco de eventos cardiovasculares relacionados à aterosclerose mesmo em indivíduos jovens infectados pelo HIV. Uma melhor compreensão dos mecanismos moleculares responsáveis por esta síndrome levará ao descobrimento de novas drogas que irão reduzir o risco cardiovascular em pacientes infectados pelo HIV que recebem HAART. [Rev Assoc Med Bras 2009; 55(5): 621-30]

Unitermos: HIV. Doenças cardiovasculares. Síndrome de Imunodeficiência Adquirida. Lipodistrofia. Terapia antirretroviral de alta atividade.

\section{References}

1. Barbaro G. Cardiovascular manifestations of HIV infection. Circulation. 2002;106:1420-5.

2. Barbaro G. Pathogenesis of HIV-associated heartdisease. AIDS. 2003;17(Suppl 1):S12-S20.

3. Barbaro G. Reviewing the cardiovascular complications of HIV infection after the introduction of higly active antiretroviral therapy. Curr Drug Targets Cardiovasc Haematol Disord. 2005;5:337-43.

4. Nzuobontane D, Blackett KN, Kuaban C. Cardiac involvement in HIV-infected people in Yaounde,Cameroon. Postgrad Med J. 2002;78:678-81.

5. Ntsekhe M, Hakim J. Impact of human immunodeficiency virus infection on cardiovascular disease in Africa. Circulation. 2005;112:3602-7.

6. Twagirumukiza M, Nikeramihigo E, Seminega B, Gasakure E, Boccara F, Barbaro G. Prevalence of dilated cardiomyopathy in HIV-infected African patients not receiving HAART: a multicenter, observational, prospective, cohort study in Rwanda. Curr HIV Res. 2007;5:129-37.

7. Barbarini G, Barbaro G. Incidence of the involvement of the cardiovascular system in HIV infection. AIDS. 2003;17(Suppl 1):S46-S50.

8. Bijl M, Dieleman JP, Simoons M, Van Der Ende ME. Low prevalence of cardiac abnormalities in an HIV-seropositive population on antiretroviral combination therapy. J AIDS. 2001;27:318-20.

9. Torre D, Pugliese A, Orofino G. Effect of highly active antiretroviral therapy on ischemic cardiovascular disease in patients with HIV-1 infection. Clin Infect Dis. 2002;35:631-2.

10. Barbaro G. HIV-associated myocarditis. Heart Failure Clin. 2005;1:439-48.

11. Barbaro G, Di Lorenzo G, Grisorio B, Barbarini G and the Gruppo Italiano per lo Studio Cardiologico dei pazienti affetti da AIDS investigators. Cardiac involvement in the acquired immunodeficiency syndrome. A multicenter clinical-pathological study. AIDS Res Hum Retroviruses. 1998;14:1071-7.

12. Klatt EC. Cardiovascular Pathology in AIDS. Adv Cardiol. 2003;40:23-48. 
13. Oddo D, Casanova M, Acuna G, Ballesteros J, Morales B. Acute Chagas disease (Trypanosomiasis amaericana) in acquired immunodeficiency syndrome: report of two cases. Hum Pathol. 1992;23:41-4.

14. Sartori AM, Lopes MH, Benvenuti LA, Caramelli B, Di Pietro A, Nunes EV, et al. Reactivation of Chagas disease in a human immunodeficiency virus-infected patient leading to severe heart disease with a late positive direct microscopic examination of the blood. Am J Trop Med Hyg. 1998;59:784-6.

15. Herskowitz A, Tzyy-Choou W, Willoughby SB, Vlahov D, Ansari AA, Bershorner WE et al. Myocarditis and cardiotropic viral infection associated with severe left ventricular dysfunction in late-stage infection with human immunodeficiency virus. J Am Coll Cardiol. 1994;24:1025-32.

16. Bowles NE, Kearney DL, Ni J, Perez-Atayde AR, Kline MW, Bricker JT, et al The detection of viral genomes by polymerase chain reaction in the myocardium of pediatric patients with advanced HIV disease. J Am Coll Cardiol, 1999;34:857-65.

17. Barbaro G, Di Lorenzo G, Soldini M, Giancaspro G, Grisorio B, Pellicelli A, et al. The intensity of myocardial expression of inducible nitric oxide synthase influences the clinical course of HIV-associated cardiomyopathy. Intern Med. 1999;7 (S1):S90.

18. Fiala M, Popik W, Qiao JH, Lossinsky AS, Alce T, Tran K, et al. HIV-1 induces cardiomyopathy by cardiomyocyte invasion and gp120, tat and cytokine signaling. Cardiovasc Toxicol. 2004;4:97-107.

19. Kan H, Xie Z, Finkel MS. HIV gp120 enhances NO production by cardiac myocytes through p38 MAP kinase-mediated NK-kB activation. Am J Physiol. 2000;279:138-43.

20. Barbaro G, Di Lorenzo G, Soldini M, Giancaspro G, Grisorio B, Pellicelli A, et al. The intensity of myocardial expression of inducible nitric oxide synthase influences the clinical course of human immunodeficiency virus-associated cardiomyopathy. Circulation. 1999;100:633-9.

21. Currie PF, Goldman JH, Caforio AL, Jacob AJ, Baig MK, Brettle RP, et al. Cardiac autoimmunity in HIV related heart muscle disease. Heart. 1998;79:599-604.

22. Lipshultz SE, Easley KA, Orav EJ, Kaplan S, Starc TJ, Bricker JT, et al. Cardiac dysfunction and mortality in HIV-infected children. The Prospective P2C2 HIV Multicenter Study. Circulation. 2000;102:1542-8.

23. Miller TL, Orav EJ, Colan SD, Lipshultz SE. Nutritional status and cardiac mass and function in children infected with the human immunodeficiency virus. Am J Clin Nutr. 1997;66:660-4.

24. Hoffman M, Lipshultz SE, Miller TL. Malnutrition and cardiac abnormalities in the HIV-infected patients. In: Miller TL, Gorbach S, editors. Nutritional aspects of HIV infection. London: Arnold; 1999. p.33-9.

25. Beck MA, Kolbeck PC, Shi Q, Rohr LH, Morris VC, Levander OA. Increased virulence of a human enterovirus (coxackievirus B3) in selenium-deficient mice. J Infect Dis. 1994;170:351-7.

26. Chariot P, Perchet H, Monnet I. Dilated cardiomyopathy in HIV-infected patients (letter). N Engl J Med. 1999;340:732.

27. Shahmanesh M, Bradbeer CS, Edwards A, Smith SE. Autonomic dysfunction in patients with human immunodeficiency virus infection. Int J STD AIDS. 1991;2:419-23.

28. Gluck T, Degenhardt E, Scholmerich J, Lang B, Grossman J, Straub RH. Autonomic neuropathy in patients with HIV: course, impact of disease stage, and medication. Clin Auton Res. 2000;10:17-22.

29. Barbaro G, Di Lorenzo G, Soldini M, Bellomo G, Belloni G, Grisorio B et al. Vagal system impairment in human immunodeficiency virus-positive patients with chronic hepatitis C: does glutathione deficiency have a pathogenetic role? Scand J Gastroenterol. 1997;32:1261-6.

30. Barbaro G, Pellicelli A, Barbarini G, Akashi YI. Takotsubo-like left ventricular dysfunction in HIV-infected patient. Curr HIV Res. 2006;4:239-41.

31. Lewis W, Grupp IL, Grupp G, Hoit B, Morris R, Samarel AM, et al. Cardiac dysfunction in the HIV-1 transgenic mouse treated with zidovudine. Lab Invest. 2000;80:187-97.

32. Lipshultz SE, Easley KA, Orav EJ, Kaplan S, Starc TJ, Bricker JT, et al. Absence of cardiac toxicity of zidovudine in infants. N Engl J Med. 2000;343:759-66.

33. Sonnenblick EH, Rosin A. Cardiotoxicity of interferon: a review of 44 cases. Chest. 1991;99:557-61.

34. Bristow MR, Mason JW, Billingham ME, Daniels JR. Doxorubicin cardiomyopathy:evaluation by phonocardiography, endomyocardial biopsy and cardiac catheterization. Ann Intern Med. 1978;88:168-75.

35. Brown DL, Sather S, Cheitlin MD. Reversible cardiac dysfunction associated with foscarnet therapy for cytomegalovirus esophagitis in an AIDS patient. Am Heart J. 1993;125:1439-41.

36. Chi D, Henry J, Kelley J, Thorpe R, Smith JK, Krishnaswamy G. The effect of HIV infection on endothelial function. Endothelium. 2000;7:223-42.

37. Twu C, Liu QN, Popik W, Bukrinsky M, Sayre J, Roberts J, et al. Cardiomyocytes undergo apoptosis in human immunodeficiency virus cardiomyopathy through mitochondrion and death receptor-controlled pathways. Proc Natl Acad Sci USA. 2002;99:14386-91.

38. Johnson RM, Little JR, Storch GA. Kawasaki-like syndromes associated with human immonodeficiency virus infection. Clin Infect Dis. 2001;32:1628-34.

39. Johnson RM, Barbarini G, Barbaro G. Kawasaki-like syndromes and othervasculitic syndromes in HIV-infected patients. AIDS. 2003;17(Suppl 1):S77-S82.
40. Barbaro G, Di Lorenzo G, Barbarini G. Kawasaki-like syndrome in an HIVinfected adult. Rheumatology. 2003;42:1427-9.

41. Shingadia D, Das L, Klein-Gitelman N, Chadwick E. Takayasus arteritis in a human immunodeficiency virus-infected adolescent. Clin Infect Dis. 1999;29:458-9.

42. Barbaro G, Barbarini G, Pellicelli AM. HIV-associated coronary arteritis in a patient with fatal myocardial infarction. N Engl J Med. 2001;344:1799-800.

43. Heidenreich PA, Eisenberg MJ, Kee LL, Somelofski CA, Hollander H, Schiller NB, et al. Pericardial effusion in AIDS. Incidence and survival. Circulation. 1995;92:3229-34.

44. Barbaro G, Fisher SD, Lipshultz SE. Pathogenesis of HIV-associated cardiovascular complications. Lancet Infect Dis. 2001;1:115-24.

45. Barbaro G, Fisher SD, Giancaspro G, Lipshultz SE. HIV-associated cardiovascular complications: a new challenge for emergency physicians. Am J Emerg Med. 2001;19:566-74.

46. Nahass RG, Weinstein MP, Bartels J, Gocke DJ. Infective endocarditis in intravenous drug users: a comparison of human immunodeficiency virus type 1-negative and -positive patients. J Infect Dis. 1990;162:967-70.

47. Barbaro G. Reviewing the clinical aspects of HIV-associated pulmonary hypertension. J Respir Dis. 2004;25:289-93.

48. Duong M, Dubois C, Buisson M, Eicher JC, Grappin M, Chavanet P, et al. Non-Hodgkins lymphoma of the heart in patients infected with human immunodeficiency virus. Clin Cardiol. 1997;20:497-502.

49. Sanna P, Bertoni F, Zucca E, Roggero E, Passega Sidler E, Fiori G, et al. Cardiac involvement in HIV-related non Hodgkin Iymphoma: a case report and short review of the literature. Ann Hematol. 1998;77:75-8.

50. Dal Maso L, Serraino D, Franceschi S. Epidemiology of HIV-associated malignancies. Cancer Treat Res. 2001;104:1-18.

51. Carr A, Samaras K, Burton S, Law M, Freund J, Chisholm DJ, et al. A syndrome of peripheral lipodystrophy, hyperlipidaemia and insulin resistance in patients receiving HIV protease inhibitors. AIDS. 1998;12:F51-F8.

52. Carr A. HIV lipodystrophy: risk factors, pathogenesis, diagnosis and management. AIDS. 2003;17(Suppl 1):S141-S8.

53. Grinspoon S, Carr A. Cardiovascular risk and body-fat abnormalities in HIVinfected adults. N Engl J Med. 2005;352:48-62.

54. Carr A, Samaras K, Chisholm DJ, Cooper DA. Pathogenesis of HIV-1 protease inhibitor-associated peripheral lipodystrophy, hyperlipidaemia, and insulin resistance. Lancet. 1998;351:1881-3.

55. Mooser V, Carr A. Antiretroviral therapy-associated hyperlipidemia in HIV disease. Curr Opin Lipidol. 2001;12:313-9.

56. Fauvel J, Bonnet E, Ruidavets JB, Ferrieres J, Toffoletti A, Massip P, et al. An interaction between apo C-III variants and protease inhibitors contributes to high triglyceride/low HDL leves in treated HIV patients. AIDS. 2001; 15:2397-406.

57. Bonnet E, Ruidavets JB, Tuech J, Ferrieres J, Collet X, Fauvel J, et al. Apoprotein C-III and E-containing lipoparticles are makedly increased in HIV-infected patients treated with protease inhibitors: association with the development of lipodystrophy. J Clin Endocrinol Metab. 2001;86:296-302.

58. Caron M, Auclair M, Sterlingot H, Kornprobst M, Capeau J. Some HIV protease inhibitors alter lamin A/C maturation and stability, SREBP-1 nuclear localization and adipocyte differentiation. AIDS. 2003;17:2437-44.

59. Murata H, Hruz PW, Mueckler M. The mechanism of insulin resistance caused by HIV protease inhibitor therapy. J Biol Chem. 2000;275:20251-4.

60. Myarcik DC, McNurlan MA, Steigbigel RT, Fuhrer J, Gelato MC. Association of severe insulin resistance with body loss and limb fat and elevated serum tumor necrosis factor receptor levels in HIV lipodystrophy. J AIDS. 2000;25:312-21.

61. Gougeon ML, Penicaud L, Fromenty B, Leclercq P, Viard JP, Capeau J. Adipocytes targets and actors in the pathogenesis of HIV-associated lipodystrophy and metabolic alterations. Antivir Ther. 2004;9:161-77.

62. Caron M, Auclair M, Lagathu C, Lombes A, Walker U, Kornprobst M, et al. The HIV-1 nucleoside reverse transcriptase inhibitors stavudine and zidovudine alter adipocyte function in vitro. AIDS. 2004;18:2127-36.

63. Lewis W, Kohler J, Hosseini S, Haase C, Copeland W, Bienstock R, et al. Antiretroviral nucleosides, deoxynucleotide carrier and mitochondrial DNA: evidence supporting the DNA pol-gamma hypothesis. AIDS. 2006;20:675-84.

64. Seminari E, Tinelli C, Minoli L, Sacchi P, Filice G, Zocchetti C, et al. Evaluation of the risk factors associated with lipodystrophy development in a cohort of HIV-positive patients. Antivir Ther. 2002;7:175-80.

65. Mc Comsey GA, Paulsen D, Lonergan JT, Hessenthaler SM, Hoppel CL, Williams VC, et al. Improvements in lipoatrophy, mitochondrial DNA levels and fat apoptosis after replacing stavudine with abacavir or zidovudine. AIDS. 2005; 19:15-23.

66. Vigouroux C, Maachi M, Nguyen TH, Coussieu C, Gharakhanian S, Funahashi $\mathrm{T}$, et al. Serum adipocytokines are related to lipodystrophy and metabolic disorders in HIV-infected men under antiretroviral therapy. AIDS. 2003; 17:1503-11

67. Haque WA, Shimomura I, Matsuzawa Y, Garg A. Serum adiponectin and leptin levels in patients with lipodystrophies. J Clin Endocrinol Metab. 2002;87:2395-8. 
68. Addy CL, Gavrila A, Tsiodras S, Brodovicz B, Karchmer AW, Mantzoros CS. Hypoadiponectinemia is associated with insulin resistance, hypertriglyceridemia, and fat redistribution in human immunodeficiency virus-infected patients treated with highly active antiretroviral therapy. J Clin Endocrinol Metab. 2003;88:627-36.

69. Kosmiski L, Kuritzkes D, Lichtenstein K, Eckel R. Adipocyte-derived hormone levels in HIV lipodystrophy. Antivir Ther. 2003;8:9-15.

70. Fiala M, Murphy T, MacDougall J, Yang W, Luque A, Iruela-Arispe L, et al. HAART drugs induces mitochondrial damage and intercellular gaps and gp120 causes apoptosis. Cardiovasc Toxicol. 2005:4:327-37.

71. Stein JH, Klein MA, Bellehumeur JL, Mc Bride PE, Wiebe DA, Otvos JD, et al. Use of human immunodeficiency virus-1 protease inhbitors is associated with atherogenic lipoprotein changes and endothelial dysfunction. Circulation. 2001;104:257-62

72. Zhong DS, LuXH, Conklin BS, Lin PH, Lumsden AB, Yao Q, et al. HIV protease ritonavir induces cytotoxicity of human endothelial cells. Arterioscler Thromb Vasc Biol. 2002;22:1560-6.

73. Chai H, Yang H, Yan S, Li M, Lin P, Lumsden AB, et al. Effects of 5 HIV protease inhibitors on vasomotor function and superoxide anion production in porcine coronary arteries. J AIDS. 2005;40:12-9.

74. Van Wanrooij EJ, Happe H, Hauer AD, De Vos P, Imanishi T, Fujiwara H, et al. HIV entry inhibitor TAK-779 attenuates atherogenesis in low-density lipoprotein receptor-deficient mice. Arterioscler Thromb Vasc Biol. 2005;25:2642-7.

75. Hadigan C, Meigs JB, Rabe J, D Agostino RB, Wilson PW, Lipinska I, et al. Increased PAI-1 and TPA antigen levels are reduced with metformin therapy in HIV-infected patients with fat redistribution and insulin resistance. J Clin Endocrinol Metab. 2001;86:939-43.

76. Witz M, Lehmann J, Korzets Z. Acute brachial artery thrombosis as the initial manifestations of human immunodeficiency virus infection. Am J Hematol. 2000;64:137-9.

77. Sullivan PS, Dworkin MS, Jones JL, Hooper WC. Epidemiology of thrombosis in HIV-infected individuals. The Adult/Adolescent Spectrum of HIV Disease Project. AIDS. 2000;14:321-4.

78. Miguez-Burbano MJ, Burbano X, Rodriguez A, Lecusay R, Rodriguez N, Shor-Posner G. Development of thrombocytosis in HIV drug users: impact of antiretroviral therapy. Platelets. 2002;13:183-5.

79. Aoun S, Ramos E. Hypertension in the HIV-infected patient. Curr Hyperten Rep. 2000;2:478-81.

80. Roling J, Schmid H, Fischereder M, Draenert R, Goebel FD. HIV-associated renal diseases and highly active antiretroviral therapy-induced nephropathy. Clin Infect Dis. 2006;42:1488-95.

81. National Cholesterol Education Program (NCEP) Expert Panel on Detection EaToHBCiAATPI. Third Report of the national Cholesterol Education Program (NCEP) Expert Panel on Detection,Evaluation, and Treatment of High Blood Cholesterol in Adults (Adult Treatment Panel III) final report. Circulation. 2002;106:3143-421

82. Gazzaruso C, Bruno R, Garzaniti A, Giordanetti S, Fratino P, Sacchi P, et al. Hypertension among HIV patients: prevalence and relationship to insulin resistance and metabolic syndrome. J Hypertens. 2003;21:1377-82.

83. Crane H, Van RompaeyS, Kitahata M. Antiretroviral medications associated with elevated blood pressure among patients receiving highly active antiretroviral therapy. AIDS. 2006;20:1019-26.

84. Sattler FR, Qian D, Louie S, Johnson D, Briggs W, DeQuattro V, et al. Elevated blood pressure in subjects with lipodystrophy. AIDS 2001;15:2001-10.

85. Barbaro G, Di Lorenzo G, Cirelli A, Grisorio B, Lucchini A, Hazra C, et al. An open-label, prospective, observational study of the incidence of coronary artery disease in patients with HIV receiving highly active antiretroviral therapy. Clin Ther. 2003;25:2405-18.

86. Bozzette SA, Ake CF, Tam HK, Chang SW, Louis TA. Cardiovascular and cerebrovascular events in patients treated for human immunodeficiency virus infection. N Engl J Med. 2003;348:702-10.

87. Friis-Moller N, Weber R, Reiss $P$, Thiebaut R, Kirk O, DArminio Monforte A, et al. Cardiovascular risk factors in HIV patients-association with antiretroviral therapy. Results from DAD study. AIDS. 2003;17:1179-93.

88. Holmberg SD, Moorman AC, Williamson JM, Tong TC, Ward DJ, Wood KC, et al. Protease inhibitors and cardiovascular outcomes in patients with HIV-1. Lancet. 2002;360:1747-8.

89. Mary-Krause M, Cotte L, Simon A, Partisani M, Costagliola D and the Clinical Epidemiology Group from the French Hospital Database. Increased risk of myocardial infarction with duration of protease inhibitor therapy in HIV-infected men. AIDS. 2003;17:2479-86.

90. The DAD Study Group. Class of antiretroviral drugs and the risk of myocardial infarction. N Engl J Med. 2007;356:1723-35.

91. Depairon M, Chessex S, Sudre P, Rodondi N, Doser N, Chave JP, et al. Premature atherosclerosis in HIV-infected individuals: focus on protease inhibitor therapy. AIDS. 2001;15:329-34.

92. Hsue PY, Lo JC, Franklin A, Bolger AF, Martin JN, Deeks SG. et al. Progression of atherosclerosis as assessed by carotid intima-media thickness in patients with HIV infection. Circulation. 2004;109:1603-8.

93. Currier JS, Kendall MA, Zackin R, Henry WK, Alston-Smith B, Torriani F, et al. Carotid artery intima-media thickness and HIV infection: traditional risk factors overshadow impact of protease inhibitor exposure. AIDS. 2005;19:927-33.

94. Alonso-Villaverde C, Coll B, Parra S, Montero M, Calvo N, Tous M, et al. Atherosclerosis in patients infected with HIV is influenced by a mutant monocyte chemoattractant protein-1 allele. Circulation. 2004;110:2204-9.

95. Maggi P, Serio G, Epifani G, Fiorentino G, Saracino A, Fico C, et al. Premature lesions of the carotid vessels in HIV-1-infected patients treated with protease inhibitors. AIDS. 2000;14:F123-F128.

96. Jerico C, Knobel H, Calvo N, Sorli ML, Guelar A, Gimeno-Bayon JL, et al. Subclinical carotid atherosclerosis in HIV-infected patients: role of combination antiretroviral therapy. Stroke. 2006;37:812-7.

97. Thiebaut R, Aurillac-Lavignole V, Bonnet F, Ibrahim N, Cipriano C, Neau D, et al. Change in atherosclerosis progression in HIV-infected patients: ANRS Aquitane Cohort, 1999-2004. AIDS. 2005;19:729-31.

98. lacobellis G, Sharma AM, Pellicelli AM, Grisorio B, Barbarini G, Barbaro G. Epicardial adipose tissue is related to carotid intima-media thickness and visceral adiposity in HIV-infected patients with highly active antiretroviral therapy-associated metabolic syndrome. Curr HIV Res. 2007:5:275-9.

99. Iacobellis G, Pellicelli AM, Sharma AM, Grisorio B, Barbarini G, Barbaro G. Relation of subepicardial adipose tissue to carotid intima-media thickness in patients with human immunodeficiency virus. Am J Cardiol. 2007:99:1470-2.

100.lacobellis G, Pellicelli AM, Grisorio B, Barbarini G, Leonetti F, Sharma AM, et al. Relation of epicardial fat and alanine aminotransferase in subjects with increased visceral fat. Obesity. 2008;16:179-83.

Artigo recebido: 05/05/09

Aceito para publicação: 15/05/09 